\title{
Pengaruh Status Kerja terhadap Tingkat Stress Belajar Mahasiswa Semester VIII
}

\author{
M. Hasan, Romiko, Efroliza
}

Program Studi Ilmu Keperawatan STIKes Muhammadiyah Palembang, Jl. Jenderal Ahmad Yani, 13 Ulu, Kecamatan Seberang Ulu II, Kota Palembang, Sumatera Selatan

E-mail : anomhasan17@gmail.com

$\begin{array}{ll}\text { Diterima tanggal } & : \text { 31 Januari 2020 } \\ \text { Direvisi tanggal } & : \text { 15 Maret 2020 } \\ \text { Dipublikasikan tanggal } & : \text { 11 Juni 2020 }\end{array}$

\begin{abstract}
Abstrak
Latar Belakang dan Tujuan: Proses belajar dan bekerja dalam waktu bersamaan dapat menimbulkan efek negatif karena prosedur perizinan untuk melanjutkan studi sulit di dapatkan calon mahasiswa dari tempat bekerja, tugas yang terlalu banyak, aturan yang membingungkan, tuntutan yang saling bertentangan, dan deadline tugas perkuliahan. National Center of Education Statistics (NCES) menemukan bahwa mahasiswa yang bekerja lebih dari 16 jam ke atas memiliki pengaruh terhadap prestasi yang lebih rendah dibanding yang tidak bekerja. Tujuan penelitian untuk mengetahui adakah pengaruh status kerja terhadap tingkat stress belajar
\end{abstract}

Metode: Penelitian ini menggunakan desain cross sectional yaitu mencari pengaruh antara variabel status kerja dan tingkat stress, uji statistik yang digunakan adalah uji Chi Square dan instrumen pengumpulan data menggunakan kuesioner yang diberikan pada mahasiswa semester VIII PSIK REG B di STIKes Muhammadiyah palembang.

Hasil : Didapatkan data pada 64 mahasiswa semester VIII PSIK Reg B STIKes Muhammadiyah Palembang bahwa dari total 32 responden yang bekerja sebanyak $10(31,3 \%)$ responden mengalami stress ringan dan $22(68,8 \%)$ responden mengalami stress berat, sedangkan dari total 32 responden yang tidak bekerja 21 $(65,6 \%)$ responden mengalami stress ringan, dan $11(34,4 \%)$ responden mengalami stress berat.

Simpulan dan Implikasi: Hasil uji statistik diperoleh p Value $=0,012 \alpha \leq 0,05$ sehingga dapat disimpulkan bahwa ada pengaruh antara status kerja terhadap tingkat stress, $\mathrm{OR}=, .238$ yang berarti bahwa responden yang telah bekerja 0,238 kali berpeluang mengalami stress berat.

Kata Kunci: Status kerja perawat; Proses belajar; Tingkat stress belajar

Sitasi: Hasan M, Romiko \& Efroliza. (2020). Pengaruh status kerja terhadap tingkat stress belajar mahasiswa semester VIII. The Indonesian Journal of Health Science. 12(1), 91-99

Copyright: (C) 2020 Hasan et al. This is an open-access article distributed under the terms of the Creative Commons Attribution License, which permits unrestricted use, distribution, and reproduction in any medium, provided the original author and source are credited.

Diterbitkan Oleh: Universitas Muhammadiyah Jember

ISSN (Print): 2087-5053

ISSN (Online): 2476-9614 


\begin{abstract}
Background and Aim: The process of learning and working at the same time can have a negative effect because licensing procedures to continue studies are difficult to get prospective students from work, too many assignments, confusing rules, conflicting demands, and lecture assignments deadlines. The National Center for Education Statistics (NCES) found that students who worked more than 16 hours and above had a lower influence on achievement than those who did not work. The studyaims to find out whether there was an effect of work status on the stress level of learning VII semester student.

Methods: This study used a cross sectional design that is looking for influence between work status variables and stress levels, the statistical test used is Chi Square test and data collection instruments using questionnaires who were given to students in PSIK REG B in the Muhammadiyah STIKes Palembang.

Results: Data obtained on 64 semester students VIII Reg B PSIK Muhammadiyah STIKes Palembang that of a total of 32 respondents who worked as many as 10 $(31.3 \%)$ respondents experienced mild stress and 22 (68.8\%) respondents experienced severe stress, while from a total of 32 respondents who did not work $21(65.6 \%)$ respondents experienced mild stress, and 11 (34.4\%) respondents $m$ experiencing severe stress.

Conclusion: The statistical test results obtained $p$ Value $=0.012 \alpha \leq 0.05$ so it can be concluded that there is an influence between work status to stress level, OR = .238 which means that respondents who have worked 0.238 times have a chance to experience severe stress .
\end{abstract}

Keywords: Learning process; Stress level of learning; Work status of nurse

\section{PENDAHULUAN}

Pada era modern seperti saat ini manusia dihadapkan dengan permasalahan yang kompleks diataranya masalah kebutuhan hidup baik primer maupun sekunder, hal tersebut menuntut manusia mencari solusi serta menyelesaikan masalah dengan cepat dan tepat, dalam proses tersebut manusia dapat mengalami tekanan fisik maupun mental sehingga menyebabkan stress. Stress merupakan masalah umum yang terjadi dalam kehidupan manusia, hal ini dikarenakan stres sudah menjadi bagian hidup yang tidak terelakan. Baik di lingkungan sekolah, kerja, keluarga, atau dimanapun. Stress juga dapat menimpa siapapun mulai dari anakanak, remaja, dewasa, lanjut usia, pekerja, pelajar, mahasiswa atau siapapun, yang dapat berdampak membahayakan fisik maupun mental. (Ashar : 2014, Kupriyanov \& zhdanov:2014)

Seiring perkembangan zaman manusia berbagai jenis kebutuhan semakin meningkat dan Kebutuhan yang krusial bagi manusia salah satunya, yakni kebutuhan akan pendidikan. Pendidikan merupakan kebutuhan manusia yang sangat penting karena pendidikan mempunyai tugas untuk menyiapkan SDM bagi pembangunan bangsa dan negara. Dalam proses pendidikan ,Stress pada mahasiswa dapat terjadi karena disebabkan ketidakmampuan dalam melakukan kewajibannya sebagai mahasiswa, di antaranya seperti untuk membayar SPP, 
membeli alat tulis lengkap,biaya fotokopi, biaya pelatihan, biaya riset/penelitian, biaya praktek bidang studi, akses internet,dan berbagai pembiayaan lain untuk memenuhi tuntutan pendidikan khususnya di perguruan tinggi. Terlebih tambahan untuk biaya hidup mahasiswa,seperti: makan, kos, bensin, service motor dan lain-lain. Kebutuhan akan hidup yang kian meningkat pula membuat mahasiswa harus mencari cara untuk mampu mencukupi kebutuhannya untuk pendidikan dan juga untuk biaya hidupnya dengan mencari jalan keluar dengan cara bekerja. (Robert, 2012).

Beragam alasan yang melatar belakangi mahasiswa untuk kuliah sambil bekerja. Alasan utamanya adalah terkait dengan finansial yakni memperoleh penghasilan untuk membayar pendidikan dan kebutuhan sehari-hari sekaligus meringankan beban keluarga. Alasan lainnya adalah untuk mengisi waktu luang dikarenakan jadwal perkuliahan yang tidak padat, ingin hidup mandiri agar tidak ketergantungan dengan orang lain ataupun orang tua, mencari pengalaman di luar perkuliahan, menyalurkan hobi. (Astiko, 2013 dalam Putri \& Savari, 2013).

Mahasiswa yang kuliah sambil bekerja memiliki efek positif, yaitu mendapat gaji, memiliki kesempatan yang lebih besar untuk memperoleh pekerjaan setelah lulus, Namun dalam proses belajar dan bekerja dalam waktu bersamaan juga dapat menimbulkan efek negatif karena tugas yang terlalu banyak, aturan yang membingungkan, tuntutan yang saling bertentangan, dan deadline tugas perkuliahan. National Center of Education Statistics (NCES) menemukan bahwa mahasiswa yang bekerja lebih dari 16 jam ke atas memiliki pengaruh terhadap prestasi yang lebih rendah dibanding yang tidak bekerja. (Gleason, 1993 dalam Metriyana:2014: 10)

Di Indonesia, penelitian yang dilakukan di Universitas Tribhuwana Tunggadewi tahun 2013 dengan judul Perbedaan tingkat stress pada mahasiswa yang bekerja dan tidak bekerja, dengan jumlah populasi 84 mahasiswa dan sampel 46 mahasiswa, terdapat 23 responden mahasiswa yang bekerja, dan 23 responden mahasiswa yang belum bekerja, hasil yang didapat menunjukkan presentase mahasiswa yang tidak bekerja di kategorikan memiliki stress ringan $(65,22 \%)$ dan yang bekerja di kategorikan stress berat $(56,52 \%)$ sehingga disimpulkan terdapat perbedaan tingkat stress pada mahaisswa bekerja dan belum bekerja. Dengan demikian status pekerjaan berpengaruh terhadap tingkat stress.(Hamadi,Joko Wiyono, Wahidayati Rahayu $\mathrm{H}$. 2016).

Dalam lingkungan akademik stress merupakan pengalaman yang paling sering dialami siswa yang sedang belajar di tingkat sekolah maupun perguruan tinggi dalam proses belajar dalam bentuk ketegangan fisik, psikis dan emosi. hal tersebut dikarenakan tuntutan akademik yang harus di hadapinya, antara lain ujian, tugas- tugas dan lain sebagainya yang berdampak pada menurunya kemampuan akademik dan dapat menyebabkan depresi (Rismalinda:2017,Das \& Sahoo ; Jayanthi,Thirunavukarasu \& Rajkumar 2015

Stikes muhammadiyah merupakan sekolah tinggi kesehatan di sumatera selatan yang berada di bawah naungan persyarikatan 
muhammadiyah, stikes muhammadiyah berdiri pada tahun 2006 melalui surat keputusan menteri pendidikan nasional (MENDIKNAS)

No.214/D/0/2006. Dengan salah satu program studinya $\mathrm{S} 1$ keperawatan dengan SK

No.HK.03.2.4.1.03508/2006.

program studi keperawatan terbagi menjadi 2 program studi yaitu reguler a ( non ektensi) dan reguler B ( ekstensi), mahasiswa reguler a adalah mahasiswa yang melanjutkan studi langsung dari SMA atau sederajat dan reguler $B$ adalah mahasiswa yang melanjutkan studi lanjutan dari diploma III, Sebagian telah bekerja dan sebagian belum bekerja, pada tahun 2019 total mahasiswa semester VII reguler B berjumlah 65 orang, yang bekerja 30 orang dan yang belum bekerja 35 orang. Dalam peraturan akademik yang berpedoman pada Buku Pedoman Penyelenggaraan Akademik STIKES Muhammadiyah Palembang (2018) mahasiswa sebagai anggota civitas akademika diposisikan sebagai insan dewasa yang memiliki kesadaran sendiri dalam mengembangkan potensi diri di perguruan tinggi untuk menjadi intelektual, ilmuwan, praktisi, dan/atau profesional, yang mampu mengembangkan ilmu pengetahuan dan teknologi serta berakhlaq mulia untuk mendukung terwujudnya masyarakat yang sehat dan islami.

Berdasarkan

studi

pendahuluan yang di lakukan oleh peneliti dari 10 orang mahasiswa stikes muhammadiyah palembang yang dibagi menjadi dua kelompok yaitu 5 orang yang telah bekerja dan 5 orang yang belum bekerja, 4 dari 5 orang yang telah bekerja menyatakan mengalami stres, dan 2 dari 5 orang yang belum bekerja menyatakan mengalami stress, oleh karena itu maka penelitian ini ingin membuktikan apakah ada pengaruh status kerja dengan beban belajar mahasiswa.

\section{METODE PENELITIAN}

\begin{tabular}{rrr}
\multicolumn{2}{c}{ Penelitian ini bersifat } \\
kuantitatif, penelitian yang
\end{tabular} memberlakukan kuantifikasi pada variabel-variabelnya, menguraikan distribusi variabel secara numerik (memakai angka absolut berupa frekuensi dan nilai relatif berupa presentase) serta kemudian menguji hubungan antar variabel dengan menggunakan formula statistik. Desain penelitian ini menggunakan deskriptif corelatif, yang bertujuan untuk mengungkapkan hubungan korelatif antar variabel,dan menggunakan pendekatan crosssectional, dalam rancangan ini peneliti melakukan pendekatan dengan cara pengumpulan data sekaligus pada suatu waktu (point time approach). Artinya, tiap subjek penelitian hanya di teliti sekali saja dan pengukuran dilakukan terhadap status karakter atau variabel subjek pada saat pemeriksaan. Rancangan penelitian ini bertujuan untuk meniliai Pengaruh status pekerjaan terhadap tingkat stress pada Mahasiswa semester VIII PSIK REG $B$ di STIKes Muhammadiyah palembang Tahun 2019.

Populasi pada penelitian ini adalah mahasiswa PSIK Reg B Semester VIII berjumlah 64 mahasiswa . Teknik pengambilan data dengan total sampling sebanyak 64 responden. Penelitian ini dilaksanakan diempat STIKes Muhammadiyah palembang Tahun 2019. Alat pengumpulan data menggunakan kuesioner sebanyak 18 
item pernyataan, uji Chi Square dengan derajat kepercayaan $95 \%(\alpha$ $0,05)$.

\section{HASIL}

Berdasarkan tabel 1 didapatkan mahasiswa STIKes Muhammadiyah PSIK Reguler B semester VIII yang bekerja berjumlah 32 orang $(50 \%)$ dan yang tidak bekerja berjumlah 32 orang (50\%). Sedangkan tabel 2 didapatkan mahasiswa STIKes Muhammadiyah PSIK Reguler B semester VIII yang mangalami stress ringan berjumlah 31 orang $(48,4 \%)$ dan stress berat berjumlah 33 orang $(51,6 \%)$. Berdasarkan tabel 3 dapat disimpulkan bahwa dari total 32 responden yang bekerja mengalami stress ringan sebanyak $10(31,3 \%)$ dan $22 \quad(68,8 \%)$ responden yang bekerja mengalami stress berat, sedangkan dari total 32 responden yang tidak bekerja 21 $(65,6 \%)$ responden mengalami stress ringan, dan $11(34,4 \%)$ responden mengalami stress berat. Hasil uji statistik diperoleh $\mathrm{p}$ Value $=0,012 \quad \alpha \leq 0,05$ sehingga dapat disimpulkan bahwa ada pengaruh antara status kerja terhadap tingkat stress, $\mathrm{OR}=0.238$ yang berarti bahwa responden yang telah bekerja 0.238 kali berpeluang mengalami stress berat.

Tabel 1. Distribusi Frekuensi Responden Berdasarkan Status Kerja Mahasiswa

\begin{tabular}{ccc}
\hline Status Kerja & Frekuensi & Persentase (\%) \\
\hline Bekerja & 32 & $50 \%$ \\
Tidak bekerja & 32 & $50 \%$ \\
\hline Jumlah & 64 & $100 \%$ \\
\hline
\end{tabular}

Tabel 2. Distribusi Frekuensi Responden Berdasarkan Tingkat Stress Mahasiswa

\begin{tabular}{ccc}
\hline Stress & Frekuensi & Persentase (\%) \\
\hline Ringan & 31 & $48,4 \%$ \\
Berat & 33 & $51,6 \%$ \\
\hline Jumlah & 64 & $100 \%$ \\
\hline
\end{tabular}

Tabel 3. Pengaruh Status Kerja Terhadap Tingkat Stress Mahasiswa (n=64)

\begin{tabular}{ccccccccc}
\hline & \multicolumn{6}{c}{ Tingkat Stress } & & \\
\cline { 2 - 6 } $\begin{array}{c}\text { Status } \\
\text { Bekerja }\end{array}$ & Ringan & \multicolumn{3}{c}{ Berat } & Jumlah & \multirow{2}{*}{ P Value } & OR \\
\cline { 2 - 6 } & $\mathbf{N}$ & $\mathbf{\%}$ & $\mathbf{N}$ & $\mathbf{\%}$ & $\mathbf{N}$ & $\mathbf{\%}$ & & \\
\hline $\begin{array}{c}\text { Bekerja } \\
\text { Tidak }\end{array}$ & 10 & 31,3 & 22 & 68,8 & 32 & 100 & & \\
bekerja & 21 & 65,6 & 11 & 34,4 & 32 & 100 & 0,012 & 0.238 \\
\hline Jumlah & 31 & & 33 & & 64 & & & \\
\hline
\end{tabular}

\section{PEMBAHASAN}

Kerja adalah perilaku dengan yang aktitivitas yang dinamis dan bernilai, tidak dapat dilepaskan dari faktor fisik, psikis dan sosial. Nilai yang terkandung dalam kerja bagi individu yang satu dengan yang lainnya tidaklah sama. Nilai tersebut dapat mempengaruhi sikap dan prilakunya dalam bekerja. Di 
Indonesia, penelitian yang dilakukan di Universitas Tribhuwana Tunggadewi tahun 2013 dengan judul perbedaan tingkat stress pada mahasiswa yang bekerja dan tidak bekerja, dengan jumlah populasi 84 mahasiswa dan sampel 46 mahasiswa, terdapat 23 responden mahasiswa yang bekerja, dan 23 responden mahasiswa yang belum bekerja.(Hamadi,Joko

Wiyono, Wahidayati Rahayu $\mathrm{H}$. 2016). Berdasarkan hasil penelitian dan data - data di atas peneliti berasumsi bahwa meskipun sulit mendapatakan izin dari tempat bekerja tidak menjadi halangan seseorang untuk melanjutkan studi di lihat dari jumlah mahasiswa yang telah bekerja dan sedang melanjukan studi di PSIK Reg B Semester VIII STIKes Muhammadiyah Palembang yaitu 32 atau $50 \%$ dari total seluruh mahasiswa.

Stress adalah respon individu, baik respon fisik maupun psikis terhadap situasi yang penuh tekanan sehingga dapat menimbukan dampak, baik dampak terhadap psikologi, fisik, maupun spiritual. Stress merupakan masalah umum yang terjadi dalam kehidupan umat manusia., stress yang ada saat ini adalah sebuah atribut kehidupan moderen. Hal ini dikarenakan stress sudah menjadi bagian hidup yang tidak bisa terelakkan. Baik di lingkungan sekolah, kerja, keluarga, atau dimanapun, stress bisa dialami oleh seseorang. Stress juga bisa menimpa siapapun termasuk anakanak, remaja, dewasa, atau yang sudah lanjut usia. Dengan kata lain, stress pasti terjadi pada siapapun dan dimanapun. Yang menjadi masalah adalah apabila jumlah stres itu begitu banyak dialami seseorang. Dampaknya adalah stress itu membahayakan kondisi fisik dan mentalnya. stress yang jumlahnya begitu banyak bisa membahayakan kepada setiap orang, termasuk mahasiswa. (Kupriyanov \& Zhdanov :2014, Lin \& Huang: 2014.)

Dalam lingkungan akademik, stress merupakan pengalaman yang paling sering dialami oleh para siswa, baik yang sedang belajar di tingkat sekolah ataupun di perguruan tinggi. Hal tersebut dikarenakan banyaknya tuntutan akademik yang harus dihadapi, misalnya ujian, tugas-tugas, dan lain sebagainya. Sejumlah peneliti telah menemukan bahwa siswa yang mengalami stres akan cenderung menunjukkan kemampuan akademik yang menurun (Rafidah, Azizah, Norzaidi, Chong, Salwani, \& Noraini, 2009; Talib \& Zia-ur-Rehman, 2012)

Di Indonesia, penelitian yang dilakukan di Universitas Tribhuwana Tunggadewi tahun 2013 dengan judul Perbedaan tingkat stress pada mahasiswa yang bekerja dan tidak bekerja, dengan jumlah populasi 84 mahasiswa dan sampel 46 mahasiswa, terdapat 23 responden mahasiswa yang bekerja, dan 23 responden mahasiswa yang belum bekerja, hasil yang didapat menunjukkan presentase mahasiswa yang tidak bekerja di kategorikan memiliki stress ringan $(65,22 \%)$ dan yang bekerja di kategorikan stress berat $(56,52 \%)$ sehingga disimpulkan terdapat perbedaan tingkat stress pada mahaisswa bekerja dan belum bekerja. Dengan demikian status pekerjaan berpengaruh terhadap tingkat stress. Hamadi, Joko Wiyono, Wahidayati Rahayu $\mathrm{H}$, 2016).

Penelitian juga pernah di lakukan di Faculty of Management sciences, University of Education, 
Okara Campus, Pakistan tahun 2013 dengan judul Assessment of stress \& stressors a study on management students dengan jumlah populasi 300 mahasiswa dan sampel 300 mahasiswa, didapatkan hasil $47,7 \%$ siswa mengalami rasa sakit di leher, menderita migrain, sakit kepala atau kesulitan bernapas, temuan ini sejalan dengan penelitian sebelumnya (McCarty, 2006; Ongori, 2007; Agolla, 2009; Agolla \& Ongori, 2009). 66,4\% mulai memikirkan masalah hari berikutnya, dll. Temuan ini konsisten dengan penelitian sebelumnya (Ongori, 2007; Topper, 2007 Agolla, 2009; Agolla \& Ongori, 2009). 55,3\% memiliki kesulitan untuk berkonsentrasi pada satu hal karena mereka memiliki banyak tugas dan masalah pada satu waktu, temuan ini menunjukkan hasil yang sama dibandingkan dengan penelitian sebelumnya (Elfering, Grebnser, Semmer, Kaier-Freiburghaus, Ponte, Witchi 2005; Agolla, 2008 ; Agolla \& Ongori, 2009).

Berdasarkan hasil penelitian dan data - data tersebut peneliti berasumsi bahwa tingkat stress dapat ditentukan oleh ketidakmampuan seseorang mengatasi tuntutan akademik di karenakan hal-hal yeng berhubungan dengan waktu, kelelahan, dan lainlain. Dan mahasiswa yang bekerja lebih berisiko mengalami stress berat di bandingkan yang tidak bekerja, di buktikan dengan hasil akdemik, berdasarkan penelitian dengan melihat hasil belajar beberapa mahasiswa, nilai rata-rata semester mahasiswa yang bekerja cenderung lebih kecil dari yang belum bekerja.

Hasil penelitian ini juga didukung oleh teori Hans selye bahwa stress sebagai respon nonspesifik dari tubuh karena banyaknya tuntutan (MorrisonValfre,2001). Dan stress merupakan keadaan yang dialami ketika ada sebuah ketidakseimbangan antara tuntuan dan kemampuan untuk mengatasinya (Lazarus \& Folkman,1984 dalam Nikmah,2015). Dikemukakan juga bahwa stress adalah sekumpulan perubahan fisologis akibat tubuh terpapar terhadap bahaya atau ancaman (Noorhana SW,2010 dalam Tussakinah dkk, 2017). Dari hasil penelitian yang telah di lakukan peneliti bersumsi bahwa pentingnya prosedur perizinan yang mudah didapat dari tempat bekerja sangat di perlukan agar mahasiswa dapat menjalani studi dengan baik, karena tuntutan pekerjaan dan tuntutan akademik yang bersamaan diakibatkan waktu, lingkungan pekerjaan, aturan pekerjaan, lingkungan kelas, jadwal, serta metode yang di terapkan dapat memicu terjadinya resiko stress berat terutama bagi mahasiswa yang telah bekerja, semakin tinggi tuntutan pekerjaan serta tuntutan akademik maka semakin tinggi resiko stress yang dialami.

\section{SIMPULAN}

Ada pengaruh status kerja terhadap tingkat stress mahasiswa. Status kerja ternyata memberikan beban tersendiri bagi mahasiswa, di mana mahasiswa yang sudah bekerja 0,238 kali berpeluang mengalami stress berat.

\section{SARAN}

Mahasiswa yang sudah bekerja diharapkan dapat memiliki manajemen waktu yang baik untuk meminimalisir tingkat stress yang mungkin di alami. Sedangkan dari 
pihak institusi penyelenggaran pendidikan diharapkan menyusun SOP yang jelas dan aplikatif agar meminimalisir beban stress mahasiswa terutama yang sudah bekerja.

\section{DAFTAR PUSTAKA}

Arsyad,Azhar. 2014. "Media Pembelajaran.”. Jakarta, PT.Rajagrafindo Persada.

Lazarus, R. S., \& Folkman, S. (1984). Stress, appraisal, and coping. New York, USA: Springer Publishing Company

Fajrilah, Nurfitriani. 2015 . "Hubungan Stress Kerja Dengan Jinerja Perawat Pelaksana Dalam Melaksanakan Pelayanan Keperawatan Di Instalasi Gawat Darurat Rumah Sakit Umum Anutapura Palu”.

Palmer, L. (2013). The relationship between stress, fatigue, and cognitive function- ing. College Student Journal, 47(2), 312-325.

Jayanthi, P., Thirunavukarasu, M., \& Rajkumar, R. (2015). Academic stress and depression among adolescents: A crosssectional study. Indian Pediatrics, 52(3), 217-219

Sujarweni, V.Wiratna. 2014. Metode Penelitian Keperawatan. Yogyakarta. Gava Medika

$\begin{array}{lcr}\text { Sugiyono. } & 2015 . & \text { Metodologi } \\ & \text { Penelitian } & \text { Kesehatan. } \\ & \text { Yogyakarta. } & \text { Nuha } \\ & \text { Medika } & \\ \text { Sugiyono. } & \text { 2017. } & \text { Metodologi } \\ & \text { Penelitian } & \text { Kesehatan. } \\ \text { Yogyakarta. } & \text { Nuha } \\ \text { Medika } & \end{array}$

Notoadmodjo, Soekidjo. 2012. Metodologi Penelitian Kesehatan. Jakarta. Rineka Cipta

Greenberg, J. S. (2006). Comprehensive stress management $10^{\text {th }}$ edition. New York, USA: McGrawHill Compenies, Inc

Agolla, J. E., \& Ongori, H. (2009). An assessment of academic stress among undergraduate students: The case of university of Botswana. Educational Research and Reviews, 4(2), 63-70.

Bartlett, D. (1998). Stress: Perspectives and processes. Philadelphia, USA: Open University Press.

Carr, D., \& Umberson, D. (2013). The social psychology of stress, health, and coping. In DeLameter, J. \& Ward, A. (Eds.). Handbook of Social Psychology (pp. 465-487). Netherlands: Springer.

Chambel, M. J., \& Curral, L. (2005). Stress in academic life: Work characteristics as predictors of student well-being and performance. Applied Psychology

Kupriyanov, R., \& Zhdanov, R. (2014). The eustress concept: Problems and out- looks. World Journal of Medical Sciences,

Wirawan. (2012). Menghadapi Stres dan Depresi. Jakarta : Platinum Publisher.

Purwati, S. (2012). Tingkat Stres Akademik Pada Mahasiswa Reguler Angkatan 2010 Fakultas Ilmu Keperawatan Universitas Indonesia. Skripsi dipublikasikan. Depok: Universitas Indonesia 
Daulay, $\quad$ S.F. (2009).

"Perbedaan Self regulated

Learning antara

Mahasiswayang Bekerja dan yang Tidak Bekerja”, Skripsi.

Dipublikasikan: Universitas Sumatera Utara.

Hipjillah, A. \& Badriyah, N. (2015). Mahasiswa Bekerja Paruh Waktu; Antara Konsumsi dan Prestasi Akademik (Studi Pada Mahasiswa Bekerja Paruh Waktu di Uno Board Game Cafe). Jurnal Ilmiah Mahasiswa Fakultas Ekonomi dan Bisnis, 3(2),

Metriyana, M. (2014). "Studi Komparatif Pengaruh Motivasi, Perilaku Belajar, Self- Efficacy dan Status Kerja terhadap Prestasi Akademik antara Mahasiswa Bekerja dan Mahasiswa Tidak Bekerja", Skripsi.
Dipublikasikan: Universitas Diponegono, Semarang.

Purwanto, H., Syah, N., \& Rani, I.G. (2013). "Perbedaan Hasil

Belajar Mahasiswa yang Bekerja dengan Tidak Bekerja Program Studi Pendidikan Teknik Bangunan Jurusan Teknik Sipil FTUNP", Jurnal CIVED ISSN 2302-334.

Dahlan , Muhamad Sopiyudin 2013 "Statistik Untuk Kedokteran Dan

Kesehatan".Jakarta.Salemba Medika

Buku Pedoman Akademik Stikes Muahammadiyah Palembang 2018

Hamalik, Oemar.2015" Proses Belajar Mengajar".Jakarta. Gava medika. 